\title{
Remembering words and how often they occurred in memory-impaired patients
}

\author{
MILTON E. STRAUSS \\ National Institute of Mental Health, Bethesda, Maryland \\ and The Johns Hopkins University, Baltimore, Maryland \\ and
HERBERT WEINGARTNER and KAREN THOMPSON
National Institute of Mental Health, Bethesda, Maryland

The recent memory impairments in Korsakoff's (KD), Huntington's (HD), and Alzheimer's (SDAT) diseases are qualitatively different from one another. All three of these clinical groups demonstrate dysfunctions in memory-learning processes that normally can be accomplished automatically. The effort-demanding memory performance of KD and HD patients, but not of SDAT patients, reflects how often an event occurred in a manner similar to that of normal age-matched controls. Defining the structure of memory and its impairment requires an opportunity to contrast the effects on memory of different forms of cognitive dysfunctions and of distinct cognitive operations.

Huntington's disease (HD), senile dementia of the Alzheimer's type (SDAT), and Korsakoff's disease (KD) are neuropsychiatric disorders in which memory impairments are prominent. Although the memory impairments in these disorders seem somewhat similar clinically, recent research has suggested important differences in their patterning in these syndromes. For example, recent or episodic memory impairments may be seen in each disorder, but patients with KD have greater access to previously acquired knowledge (semantic memory) than do patients with SDAT (Weingartner, Grafman, Boutelle, Kaye, \& Martin, 1983). Despite great difficulty in recall from semantic or episodic memory, patients with HD may recognize material they no longer recall and can accurately predict their recognition abilities (Brandt, in press). This distinction between episodic and semantic memory functions has been of great interest to many cognitive researchers (e.g., Cermak, 1984). Researchers have explored a number of other types of dissociations in memory pathologies and have argued for the distinctiveness of procedural versus declarative memory (Cohen \& Squire, 1980), incidental versus intentional retrieval, or remembering with or without knowing (Jacoby \& Witherspoon, 1982). Further description of contrasting memory impairments would be useful in the analysis of the psychobiological distinctiveness of these disorders, and in defining the psychobiological determinants of distinctive cognitive operations. This study examines memory in these dis-

The work of Milton E. Strauss was supported in part by NIMH Grant IR0 1MH 38387 and NIH Grant 5P0 1 NS16375. Please address reprint requests to: H. Weingartner, Laboratory of Psychology and Psychopathology, Building 10/4C116. National Institute of Mental Health, Bethesda, MD 20205. orders, using measures which permit the separate examination of aspects of cognitive operations which are effortdemanding and those that appear to occur more automatically in learning and memory operations.

The distinction between automatic and effort-demanding processes has been a useful heuristic in studies of human and infrahuman learning and memory (Hasher \& Zacks, 1979; Lewis, 1979). Automatic processes are those that occur without conscious intention and whose operation is not improved with increases in motivation. They are difficult to control once initiated and proceed without intention. Effort-demanding or controlled processes are more volitional; they require the effort or sustained attention and intent of the organism. Competing tasks or specific aspects of stimulus structure interfere with the efficiency of controlled processes. Studies of clinical populations, such as depressed patients and aged adults, suggest that effort-demanding processes are disrupted, but automatic processes in memory remain relatively unperturbed (Weingartner, in press $a$, in press $b$, in press $c$; Weingartner, Burns, Diebel, \& LeWitt, 1984; Weingartner, Rudorfer, Buchsbaum, \& Linnoila, 1983). Psychopharmacologic probes, such as amphetamine, Ldopacarbidopa, and other drugs with arousing-activating properties, also seem to selectively affect effortdemanding processes (Newman, Weingartner, Smallberg, \& Calne, in press). In general, it appears that effortdemanding cognitive processes are more vulnerable to disruption than are automatic processes, though the range of conditions in which these observations have been made is somewhat limited. In this study, we sought to determine whether there were dissociable impairments in automatic and effortful processes within episodic or recently acquired memory in HD, KD, and SDAT patients. 
tomatic and effortful processes within episodic or recently acquired memory in $\mathrm{HD}, \mathrm{KD}$, and SDAT patients.

\section{METHOD}

\section{Subjects}

Patients with HD $(\mathrm{N}=13)$ from the Baltimore Huntington's Disease Center Without Walls participated in this study along with SDAT patients $(\mathrm{N}=9), \mathrm{KD}$ patients $(\mathrm{N}=7)$, and normal controls $(\mathrm{N}=17)$, all from the Clinical Research Center of NIMH. The HD patients ranged in age from 31-61 (mean $=43.2, \mathrm{SD}=11.7$ ) and had an average of 11.2 years of education $(\mathrm{SD}=3.2$, range $=6-15$ ). Patients with SDAT (mean age $=61.4, \mathrm{SD}=3.6$, range $=51-69$ ) and $\mathrm{KD}$ (mean age $=58.7, \mathrm{SD}=4.5$, range $=53-66$ ) were matched with normal controis for age (mean $=60.0, S D=6.1$, range $=50-67$ ) and education. The mean educational attainment in years was 11.2 for HD patients ( $S D=3.2$, range $=6-15$ ), 15.3 for SDAT patients $(\mathrm{SD}=3.11$, range $=12-20), 12.12$ for $\mathrm{KD}$ patients $(\mathrm{SD}=4$, range $=12-13)$, and 14.2 for controls $(S D=3.5$, range $=12-20)$.

\section{Procedure}

Each participant was told to listen carefully to a long series of words because questions would be asked about them afterward. A list of 90 words was then read at the rate of 1 word $/ 2 \mathrm{sec}$. The list consisted of 27 different words that occurred a variable number of times. Four words were presented once; 5 , twice; 6 , three times; 6 , four times; 3 , five times; 2 , six times; and 1 , seven times. After the first list was read, the participant was asked to recall as many of the words as possible. Following this, each word on the list was read, and the participant was asked to estimate how many times it had been read before. This frequency-estimation list also contained 3 words that had not appeared on the original list. After the frequencies of occurrence were estimated for these words, a second list of 90 words was presented following the same sequence of steps. The distribution of repeated words on the second list was the same as that on the first list, and order of lists was counterbalanced (cf. Hasher \& Zacks, 1979).

\section{RESULTS AND DISCUSSION}

Table 1 summarizes the recall performance of all subject groups on both lists. As may be seen in the table, there is substantial range of recall in each of the groups, although each clinical group recalled fewer words than did normal controls, who recalled an average of half of the list. Differences among groups were significant $[F(3,42)=14.9458, p<.0001]$; the major source of variation was between the normal controls and each of the clinical groups. The differences between the normal controls and each of the clinical groups were significant

Table 1

Word Recall of Subject Groups

\begin{tabular}{lcccc}
\hline & $\begin{array}{c}\mathrm{HD} \\
(\mathrm{N}=13)\end{array}$ & $\begin{array}{c}\mathrm{KD} \\
(\mathrm{N}=7)\end{array}$ & $\begin{array}{c}\text { SDAT } \\
(\mathrm{N}=9)\end{array}$ & $\begin{array}{c}\mathrm{NC} \\
(\mathrm{N}=17)\end{array}$ \\
\cline { 1 - 1 } & $1-48$ & $0-22$ & $0-20$ & $10-44$ \\
$\begin{array}{l}\text { Number Recalled } \\
\text { Range }\end{array}$ & & & & \\
$\begin{array}{l}\text { Proportion Recalled } \\
\quad \text { Mean }\end{array}$ & .24 & .16 & .09 & .52 \\
SD & .23 & .13 & .12 & .17 \\
\hline
\end{tabular}

Note-Maximum $=54$. (ps $<.05$, Scheffé test), although the patient groups did not differ significantly among themselves.

The level of impairment of the three patient groups was also comparable on the Wechsler Memory Scale (WMS), a measure of general memory impairment that had been administered to the KD and SDAT patients. The mean score was 74.1 for $\mathrm{HD}$ subjects $(\mathrm{SD}=15.4$, range 45-100), 88.4 for KD subjects ( $S D=11.8$, range $76-112$ ), and 73.1 for SDAT subjects ( $S D=16.6$, range 50-92) $[F(2,26)=2.56, p<.05]$. The WMS scores for the HDs were estimated by regression from a clinical screening instrument, the Mini Mental State Examination (MMSE), which correlates significantly with the WMS (Folstein, Folstein, \& McHugh, 1975). The regression equation was based on the correlation between WMS and MMSE in a sample of $18 \mathrm{HD}$ patients $(r=.83, \mathrm{p}<.001]$.

It has been well established that repetition of to-beremembered material facilitates recall on word-learning tasks. This facilitation is due at least in part to the increased opportunity for encoding of frequently repeated words. Encoding and rehearsal of to-be-remembered elements require attention and effort. Differences in the relation between presentation repetition and probability of recall seen in normals and in each of the patient groups could indicate disturbances in effort-demanding processes. The top panels of Figure 1 present the curves describing this relation in each patient group in contrast with the normal controls. The words which occurred five, six, and seven times were pooled in order to have approximately equal numbers of words in each of the frequency-ofoccurrence categories.

Inspection of these curves suggests that repetition frequency facilitated the recall of HD and KD patients, even though the absolute level of word recall was well below that of normals. This suggestion was confirmed by ANOVAs which showed a linear relationship between repetition frequency and recall for HD patients $[F(1,12)$ $=37.65, \mathrm{p}<.001]$, for $\mathrm{KD}$ patients $[F(1,6)=8.41$, $p<.03]$ and, of course, for the normal controls $[F(1,16)$ $=14.13, \mathrm{p}<.002]$, but not for the SDAT patients $[F(1,8)=1.79, p<.20]$. The curves for the three patient groups appear to differ. This impression was tested by the interaction term in a groups $\times$ repetition frequency ANOVA, which was significant $[\mathrm{F}(8,104)=2.39$, $\mathrm{p}<.05]$. HD and KD groups both showed greater recall than SDATs for items presented five to seven times (ps $<.05$, Scheffé test); other comparisons were not significant. In each of these analyses, degrees of freedom were adjusted following the Greenhouse-Geisser method to account for heterogeneity of variance-covariance (Winer, 1971).

Judgments of actual frequency of occurrence appear to be associated with automatic memory operations; their accuracy is not affected by motivation, intelligence, mood, or pharmacological interventions (Hasher \& Zacks, 1979; Newman et al., in press; Weingartner, in press a; Weingartner et al., 1984). The lower half of Figure 1 shows the relation between estimated frequency and actual fre- 
EFFORT DEMANDING AND AUTOMATIC COGNITIVE PROCESSES IN SENILE DEMENTIA OF AN ALZHEIMER'S TYPE
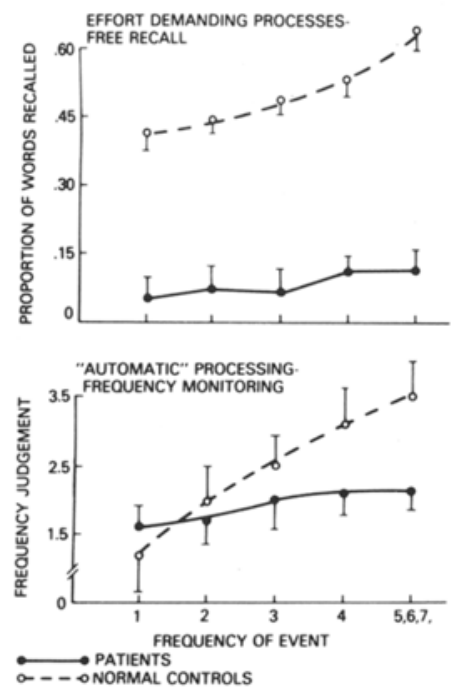

EFFORT DEMANDING AND AUTOMATIC COGNITIVE PROCESSES IN HUNTINGTON'S DISEASE
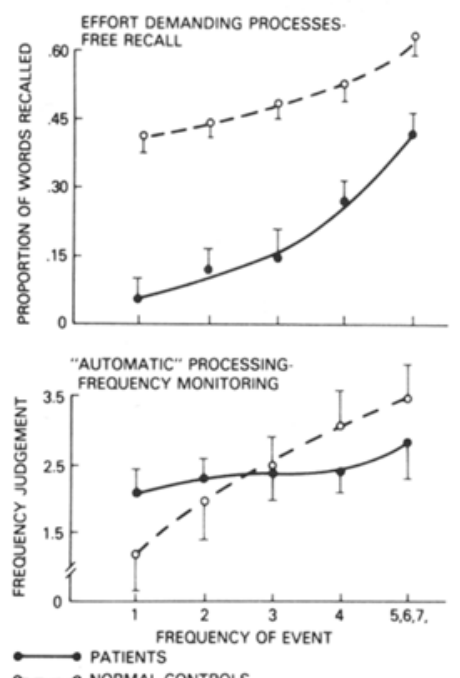

- $-\infty$ NORMAL CONTROLS
EFFORT DEMANDING AND AUTOMATIC COGNITIVE PROCESSES IN KORSAKOFF'S DISEASE
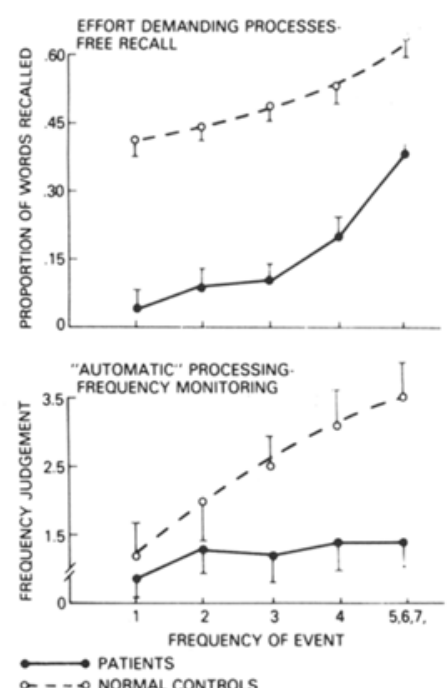

Figure 1. Effort demanding and automatic processing in memory impaired patients.

quency of words on the list for each patient group, in comparison with the normal controls.

As can be seen, there is an orderly increase in the frequency judgment of normals. Although they tend to underestimate actual frequency, there is a substantial linear relationship between actual frequency of occurrence and the frequency monitoring report of the normal controls $[F(1,16)=58.23, \mathrm{p}<.0001]$. The curves for the patient groups are much flatter and show that frequency monitoring was quite poor in these groups. Indeed, there is no relationship between judged and actual frequency among the SDAT patients $[\mathrm{F}(1,8)=1.28, \mathrm{p}<.3]$, and there was only a marginally significant relationship among the $\mathrm{KD}$ patients $[\mathrm{F}(1,24)=3.15, \mathrm{p}<.07]$. The KD patients' frequency-monitoring estimates tended to be higher for the more frequently occurring words than for the less frequently occurring words. However, the average difference between estimates for the last and most frequent categories was only 0.5 . HD patients appeared to do somewhat better, although the shape of their curve is quite different from that of normals. The relationship between actual and judged frequencies is significant $[\mathrm{F}(1,48)=$ $9.26, \mathrm{p}<.001]$. There is a more regular increase in their estimates as actual frequency increases, but the largest difference, that between the category of most frequently occurring words (2.9) and once-occurring words (2.1) of 0.8 , is much smaller than that for the normal control ( 1.28 for words occurring once and 3.51 for words occurring five, six, or seven times).

These data indicate that SDAT patients are unable to monitor event frequency and unable to make use of repetition as an aid in encoding. The recall of the memoryimpaired groups is identical for items presented only once.
Clearly, each of these patient groups, including HD and KD groups, demonstrate obvious and profound disturbance in memory under attention-effort demanding conditions (Weingartner, Grafman, Boptelle, Kaye, \& Martin, 1983). However, like recall of normals and unlike recall of SDAT patients, KD and HD patients' recall was affected by the encoding condition of repeated presentation.

The similarities of the shapes of the curves showing an increased probability of recall as a function of repetition frequency of these two patient groups and the normals are striking, and in marked contrast to the curves on the frequency-monitoring measure. The similarities indicate the importance of considering encoding opportunities when describing the recall deficits of memory-impaired patients. In mildly impaired groups such as elderly or in pseudodementia or depression and Parkinson's disease, automatic processes appear unaffected, but effortdemanding processes are impaired (Weingartner, in press a, in press $b$ ). In contrast, the present data may be taken to suggest greater impairment of automatic processing than effortful processing in some neuropathological groups. The data suggest that mechanisms mediating automatic and effortful processes are dissociable, and this hypothesis merits confirmation and extension in other patient samples and with other methods. It is also clear that additional studies should consider the relationship between changes in automatic and effort-demanding processes to other dissociable memory processes such as memory for skills versus facts, and memory with or without "conscious" awareness. This type of research can be most effectively accomplished when findings from memory-impaired patients can be compared to features of distinctive cognitive processes in parallel studies of unimpaired subjects. 
tive cognitive processes in parallel studies of unimpaired subjects.

\section{REFERENCES}

Brand, J. (in press). Access to knowledge in the dementia of Huntington's disease. Developmental Neuropsychology.

Cermak, L. S. (1984). The episodic-semantic distinction in amnesia. In N. Butters \& L. Squire (Eds.), The neuropsychology of memory. New York: Guilford Press.

Cohen, N., \& SQuire, L. (1980). Preserved learning and retention of pattern analyzing skills in amnesia: Dissociation of knowing how and knowing that. Science, 210, 207-210.

Folstein, M. F., Folstein, S. E. \& McHugh, P. R. (1975). "Minimental state": A practical method for grading the cognitive state of patients for the clinician. Journal of Psychiatric Research, 12, 189-198.

HASHER, L., \& ZACKS, R. T. (1979). Automatic and effortful processes in memory, Journal of Experimental Psychology: General, 83, 356-388.

J ACOBY, L. L., \& WITHERSPOON, D. (1982). Remembering without awareness. Canadian Journal of Psychology, 36, 300-324.

LEWIS, D. J. (1979). Psychobiology of active and inactive memory. Psychological Bulletin, 86, 1054-1083.

Newman, R. P., Weingartner, H., Smallberg, S., \& Calne, D. (in press). Effortful and automatic memory processes: Effects of dopamine. Archives of Neurology.

WeINGARTNER, H. (in press a). Automatic and effort-demanding cognitive processes in depression. In L. Poon (Ed.), Handbook for clerical memory assessment for older adults. American Psychological Association.

WeINGARTNER, H. (in press b). Comparison of memory loss associated with normal aging and pathological states. New York Academy of Science.

WeIngartner, H. (in press c). A psychological analysis of cognitive failures. Archives of General Psychiatry.

Weingartner, H., Burns, S., Diebel, R., \& LeWitt, P. (1984). Cognitive impairments in Parkinson's Disease: Distinguishing between effort-demanding and automatic cognitive processes. Psychiatry Research, 11, 223-235.

Weingartner, H., Grafman, J., Boutelle, W., Kaye, W., \& MarIIN, P. R. (1983). Forms of memory failure. Science, 221, 380-382.

Weingartner, H., Rudorfer, M. V., Buchsbaum, M. S., \& LiNNOILA, M. (1983). Effects of serotonin on memory impairments produced by ethanol. Science, 221, 472-473.

WINER, B. J. (1971). Statistical principles in experimental design (2nd ed.). New York: McGraw-Hill.

(Manuscript received November 19, 1984; revision accepted for publication August 2, 1985.) 